\title{
Echolocation inter-click interval variation among specific behaviours in free-ranging bottlenose dolphins from the coast of Uruguay
}

\author{
JAVIER S. TELLECHEA \\ Área de Anatomía, Facultad de Veterinaria, Universidad de la República, Lasplaces 1620, 11600, Montevideo, Uruguay
}

\begin{abstract}
To assess whether behaviour can be inferred from echolocation trains (inter-click intervals) this study examines acoustic recordings of free-ranging bottlenose dolphins using Passive Acoustic Monitoring (PAM). Inter-click intervals from 17 groups of free-ranging bottlenose dolphins were monitored over a 36 day period in an area within the Cerro Verde (Marine Protected Area), Uruguay. Simultaneous visual observations were made from shore nearby. Results show that inter-click intervals in the echolocation trains had significant differences for three specific behaviours: feeding, socialising and travelling. The natural environment was quiet, with no disturbances in the immediate vicinity from boats, drones or other man-made noises.
\end{abstract}

KEYWORDS: ECHOLOCATION; BEHAVIOUR; BOTTLENOSE DOLPHIN; PASSIVE ACOUSTIC MONITORING

\section{INTRODUCTION}

Many studies of cetaceans rely purely on behavioural observations during surfacing, but details of behaviour can be difficult to identify accurately from visual observations conducted at the surface (Nuuttila et al., 2013). Cetaceans are only visible at the surface for between 1 to $10 \%$ of the time (Tyack and Miller, 2002), therefore studying the sounds emitted by cetaceans makes bioacoustics a very good tool to use to describe the activity of animals (Martin and Reeves, 2002).

Toothed whales have evolved biosonar systems to locate prey and acquire information about their surroundings ( $\mathrm{Au}$, 1993; Norris et al., 1961; Surlykke and Nachtigall, 2014; Wood and Evans, 1980). The echoes returned from biosonar signals emitted by the animal are used to determine the direction and distance to potential prey items or obstacles in the water (Au, 1993; Madsen and Surlykke, 2013; Surlykke and Nachtigall, 2014). Odontocete echolocation has been extensively studied, a primary focus being the beam axis (Au, 1993; Kyhn et al., 2009; Nachtigall and Moore, 1988; Thomas and Kastelein, 1990; Villadsgaard et al., 2007). Like toothed whales, bottlenose dolphin (Tursiops truncatus) emit different types of vocalisations for different behaviours (Acevedo-Gutiérrez and Stienessen, 2004; Janik, 2009; Nowacek, 1999; Nowacek, 2005; Quick and Janik, 2008; Simard et al., 2011; ECS, 1993) and they use biosonar for foraging (Au, 1993; Herzing, 1996; Nowacek, 2005) and orientation (Simard et al., 2010). Bottlenose dolphin echolocation clicks are broadband pulses with high peak frequencies (up to $130 \mathrm{kHz}$ ), high source levels (180227B re 1 Pa peak-to-peak), short duration (individual pulses $8-70 \mu \mathrm{s}$ ), and moderate to high directionality (3dB beamwidth $10^{\circ}-40^{\circ}$, Au et al., 1978; Au et al., 1986; Au et al., 1974; Moore et al., 2008; Wahlberg et al., 2011). Inter-click intervals (ICIs) vary with context (Au, 1993). Bottlenose dolphins steadily decrease their ICIs with decreasing distance to a target (e.g. Jensen et al., 2009; Ridgway et al., 2015). However, odontocete echolocation does not appear to be limited to this model. A study of a captive beluga whale (Delphinapterus leucas) found that when the target was greater than $100 \mathrm{~m}$ the whale emitted packets of clicks in which the intervals were less than the two-way transit time, but the intervals between the packets were greater than the two-way transit time (Turl and Penner, 1989).

The ability to process a series of echolocation clicks produced at a small ICI rate rather than the two-way travel time has also been demonstrated using a trained bottlenose dolphin in a natural environment (Finneran, 2013; Finneran, 2014; Ivanov, 2004). Penner (1988) found that when dolphins are in the presence of a target of unknown distance, captive bottlenose dolphins would begin acoustic searching behaviour by echolocating at pulse rates appropriate for the maximum distance they expect to encounter the target. Sperm whales (Physeter macrocephalus), Cuvier's (Ziphius cavirostris) and Blainville's (Mesoplodon densirostris) beaked whales alter their ICIs from slow, relatively constant foraging clicks, to a rapid ICI (buzzing) during final approach to prey (Johnson et al., 2008; Johnson et al., 2004; Madsen et al., 2002; Miller et al., 2004). A similar pattern when approaching a target has also been observed in harbour porpoises (Phocoena phocoena; Verfuß et al., 2009) and in a free-swimming bottlenose dolphin (Ridgway et al., 2015). For bottlenose dolphins, studies have shown that echolocation ICI varies with different behaviours (Jones and Sayigh, 2002), and that during foraging, bottlenose dolphins produce shorter and faster ICIs (termed feeding buzzes) hence faster or slower click train emission, with the shortest ICIs reported between 3.0 and $7.1 \mathrm{~ms}$ (Wahlberg et al., 2011). In fact, the feeding activities for cetaceans typically involves fast echolocation click trains with a minimum ICI of $<10 \mathrm{~ms}$ (Carlström, 2005; DeRuiter et al., 2009; Dibble et al., 2016; Miller, 2010; Ridgway et al., 2015; Ridgway et al., 2018; Ridgway et al., 2014; Verfuß et al., 2009; Wisniewska et al., 2012), an extremely short ICI.

The odontocetes sonar system performance (directionality and sound pressure level, SPL) depends on the source parameters of the transmitted echolocation clicks, and analysis of click properties can therefore convey valuable information about the acoustic physiology and behavioural 
ecology of recorded odontocetes species (Au, 1993; Madsen and Wahlberg, 2007).

Most echolocation studies involve captive specimens performing an echolocation task with man-made targets at relatively long and static ranges (Wisniewska et al., 2014). Contemporaneously with these earlier captive studies, the development of new technology meant there were more results from animals in their natural habitat, which allowed new data to be obtained. (Aguilar Soto et al., 2008; de Freitas et al., 2015; DeRuiter et al., 2009; Johnson et al., 2004; Ladegaard et al.; Miller et al., 2004; Ridgway et al., 2015).

The aim of this study was to examine and describe the inter-click interval in the echolocation click trains among groups of free-ranging bottlenose dolphins in relation to different behaviours. Additionally, the occurrence (percentage) of potential feeding buzzes based in ICI criteria was examined for each behavioural category. This study will provide new and extensive data on whether click trains can relate to a specific behaviour and across several species.

\section{METHODS}

\section{Study area}

Data were collected on 36 non-consecutive days between March of 2017 to April 2018 in the Cerro Verde (Green hill - Marine Protected Area - $33^{\circ} 38^{\prime} \mathrm{S}, 53^{\circ} 24^{\prime} \mathrm{W}$ ) of the Atlantic coast in Uruguay (Fig. 1). Visual observations were conducted by two to four observer teams with sea states $\leq 3$ over a visible sea-surface area of approximately $500 \mathrm{~m}$ radius around the passive acoustic monitoring (PAM) stations. The visual observation point was a $30 \mathrm{~m}$ hill rounded by beaches. Two PAM underwater stations were deployed $100 \mathrm{~m}$ from shore at a depth of $3 \mathrm{~m}$ and these were placed the day before in the designated positions.

Bottlenose dolphins occur year-round in the Atlantic coastal waters of Uruguay, using the coastal zone mainly for feeding, socialising and reproduction (Fruet et al., 2014; Laporta et al., 2016; Menchaca et al., 2019; Ott et al., 2016; Tellechea et al., 2014). Groups are variable in size and age composition, ranging from one to 30 individuals, with larger groups also including calves (Laporta et al., 2016; Menchaca et al., 2019; Tellechea et al., 2014).

\section{Data collection}

During animal sightings, observers recorded behaviour, group size, travel direction, group composition and group cohesion. Binoculars with magnification $7 \mathrm{x} 50 \mathrm{~mm}^{2}$ were used to aid in the detection and tracking of animals. A group was described as a number of dolphins in close association, within approximately $100 \mathrm{~m}$ of one another and often engaged in the same activity (Bearzi et al., 1999; Shane, 1990). To ensure that the acoustic and visual data originated from the same group, all periods with multiple groups were excluded from the analysis.

The area was continuously monitored from dawn until dark. When a group of dolphins were sighted that were in the $500 \mathrm{~m}$ range (distance at which the binoculars could distinguish the behaviour) this focus group was monitored. A 10 minute observation of the group was then carried out and the precise time this observation began was noted. The clock of the PAM station recording device was synchronised with the time of day; therefore it was possible to obtain the recording made by the PAM station at the exact moment of that of the dolphin observation group. The time observation was every 5 minutes and if the group was in the $500 \mathrm{~m}$ recording range, it would be taken again for 10 minutes and so on describing the behaviour in each 10 minute tandem every 5 minutes (Piwetz, 2019; Quick and Janik, 2008).

Behaviour was recorded using the following categories: foraging/feeding (visible surface foraging and prey pursuit/capture where fish were seen fleeing, tossed about, or in the dolphin's mouth, fish shoals visible under the surface and demersal foraging consisting of repetitive, long feeding dives in the same location), socialising (physical contact, chasing each other, mating, synchronised movement, aggression and play), aerial behaviour, travelling, and milling (where dolphins are moving in varying directions with no observable surface behaviour) (Bearzi et al., 1999; Shane, 1990). Because of the low number of observations in some of the behaviour categories (e.g. only 10 minutes of resting behaviour), only the foraging/feeding, socialising and travelling categories were used for analysis. Typically, the term foraging describes the search for food while feeding is the actual event of food intake.

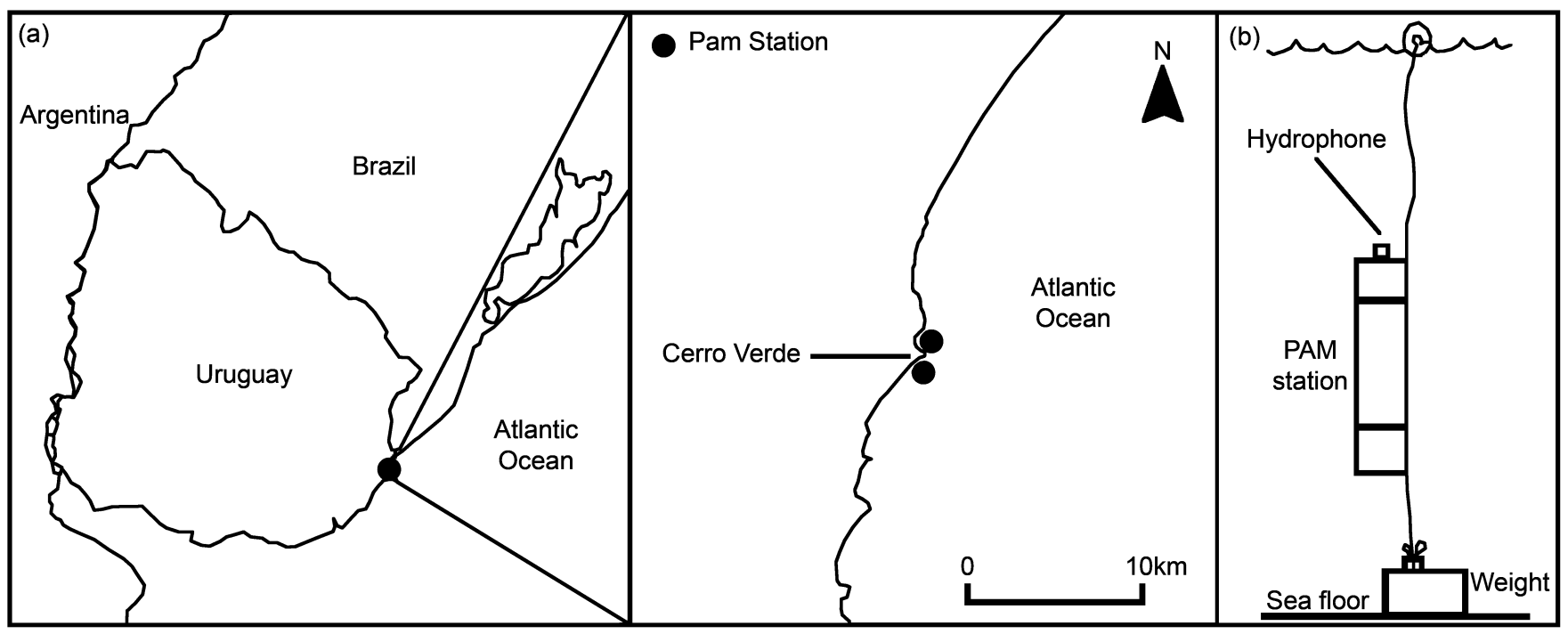

Fig. 1. Map of Uruguay and the Atlantic coast of Uruguay showing the position of the PAM buoys (A) and location of the PAM station underwater (B). 
Because of other dolphin species in the area (Tellechea et $a l ., 2016)$ and the omnidirectional recording system it was important to ensure that only single-species groups of bottlenose dolphins were present during recording sessions. Therefore, only groups recorded under excellent weather conditions that allowed unambiguous confirmation were used for analysis.

Acoustic monitoring was conducted with a home-made PAM underwater station, an acoustic self-contained data logger, comprising a hydrophone, digital memory, and power source. These PAM stations are commonly used in acoustic monitoring of several marine mammals species in Uruguay (Tellechea et al., 2014; Tellechea et al., 2016) and were set to continuously record for $48 \mathrm{~h}$ with a calibrated omnidirectional Aquarian hydrophone $\mathrm{H} 1 \mathrm{a}$ (useful range: $1 \mathrm{~Hz}$ to $100 \mathrm{KHz}$, $100 \mathrm{KHz}=-220 \mathrm{~dB}$ re: $1 \mathrm{~V} / \mu \mathrm{Pa}$ ). This was connected to an amplifier with antialiasing filter and a TASCAM DR-100mklll digital recorder with maximum resolution of 24 bits $(96 \mathrm{kHz}$, sample rate $=192 \mathrm{kHz}$ ) stored data in SD card. A voltage regulator was built to keep the system working for $48 \mathrm{hrs}$.

Recordings were analysed using custom-made scripts in MATLAB 7 (Natick, MA, USA) and Audacity free software, Version 1.2.3 (Mazzoni, 2006). Bottlenose dolphin click trains were analysed manually, and high quality click trains from single dolphins were chosen for the analysis. Files containing overlapping echolocation from more than one dolphin were omitted from the analysis. This was important in order to determine the ICI of individuals, since overlapping pulse trains would artificially increase the pulse rate.

\section{Statistical analyses}

Descriptive statistics were performed using PAST software (Hammer et al., 2001) to provide mean, standard deviation, maximum and minimum values for ICIs for each train for observed feeding, socialising and travelling behaviours. To test data normality assumptions and variance homogeneity Shapiro-Wilk and Levene test were used. As data did not meet the criteria Kruskal-Wallis and Mann-Whitney tests were used for non-parametric analysis (Zar, 2010).

The ICIs acoustic dataset was then inspected for underlying structure using multidimensional scaling (MDS), the number of dimensions used was two and used BrayCurtis distance (Borg and Groenen, 2005). Patterns in the distribution of ICIs were used to identify distinct groups of behaviour. An analysis of similarity (ANOSIM) was also used to investigate the similarity within predefined groups of ICI characteristics for the behavioural categories. For all tests, the level of significance was $\alpha=0.05$.

Several studies (Carlström, 2005; DeRuiter et al., 2009; Dibble et al., 2016; Miller, 2010; Ridgway et al., 2015; Ridgway et al., 2018; Ridgway et al., 2014; Verfuß et al., 2009; Wisniewska et al., 2012) reported fast click trains with a minimum ICI of $<10 \mathrm{~ms}$ which were found to be in relation to potential feeding activity. With this information, the percentage of ICI $<10 \mathrm{~ms}$ was calculated for each behavioural category. This was to see if there were higher percentages of ICI $<10 \mathrm{~ms}$ when feeding behaviour was observed.

To ensure that the acoustic and visual data originated from the same group of animals, all periods with multiple groups were excluded from the analysis.

\section{RESULTS}

Seventeen groups of bottlenose dolphins with acoustic recordings were sighted during the days of deployment and 625 high quality clicks trains (10,638 pulses) were selected for analysis. Clicks were recorded during feeding (333 clicks trains; 5,340 clicks), socialising (154 click trains, 2,800 clicks) and travelling (147 clicks trains, 2,498 clicks).

Table 1

Group identification, group size, pulses analysed, click trains and the corresponding behaviour data for 17 groups of bottlenose dolphins from the Atlantic coast of Uruguay.

\begin{tabular}{|c|c|c|c|c|c|}
\hline Group id (date) & Group size & Ten minutes record number & Pulses & Click trains & Behaviour \\
\hline $23 / 04 / 2017$ & 5 & 3 & 1,005 & 29 & Feeding \\
\hline $11 / 05 / 2017$ & 4 & 2 & 125 & 27 & Socialising \\
\hline $15 / 06 / 2017$ & 3 & 3 & 317 & 38 & Socialising \\
\hline $13 / 08 / 2017$ & 8 & 4 & 224 & 16 & Socialising \\
\hline $26 / 09 / 2017$ & 3 & 3 & 444 & 37 & Travelling \\
\hline $25 / 11 / 2017$ & 12 & 7 & 415 & 30 & Feeding \\
\hline $25 / 11 / 2017$ & 12 & 6 & 309 & 28 & Feeding \\
\hline $25 / 11 / 2017$ & 8 & 5 & 293 & 24 & Feeding \\
\hline $25 / 11 / 2017$ & 8 & 3 & 191 & 29 & Feeding \\
\hline $14 / 12 / 2017$ & 5 & 2 & 330 & 30 & Travelling \\
\hline $27 / 12 / 2017$ & 3 & 3 & 180 & 17 & Travelling \\
\hline $27 / 01 / 2018$ & 2 & 9 & 883 & 47 & Feeding \\
\hline $28 / 01 / 2018$ & 7 & 6 & 321 & 17 & Feeding \\
\hline $28 / 01 / 2018$ & 4 & 4 & 244 & 22 & Feeding \\
\hline $28 / 01 / 2018$ & 4 & 4 & 188 & 13 & Feeding \\
\hline $28 / 01 / 2018$ & 3 & 3 & 234 & 11 & Feeding \\
\hline $04 / 02 / 2018$ & 2 & 7 & 210 & 17 & Travelling \\
\hline $04 / 02 / 2018$ & 2 & 5 & 168 & 4 & Travelling \\
\hline $22 / 02 / 2018$ & 3 & 5 & 521 & 19 & Socialising \\
\hline $27 / 03 / 2018$ & 6 & 3 & 613 & 14 & Socialising \\
\hline $28 / 03 / 2018$ & 3 & 2 & 726 & 33 & Socialising \\
\hline $04 / 10 / 2018$ & 2 & 3 & 132 & 22 & Travelling \\
\hline $02 / 11 / 2018$ & 6 & 6 & 533 & 19 & Feeding \\
\hline $02 / 11 / 2018$ & 6 & 7 & 917 & 43 & Feeding \\
\hline $23 / 11 / 2018$ & 4 & 5 & 346 & 17 & Feeding \\
\hline $23 / 11 / 2018$ & 4 & 6 & 769 & 31 & Feeding \\
\hline
\end{tabular}


The sightings are shown in Table 1. A total of 16 minutes of echolocation was obtained, divided into 174 recordings of 10 minutes (feeding: 74 ten minutes records; socialising: 19 ten minutes records; travelling: 34 ten minutes records) and included groups of 2 to 12 dolphins $($ mean $=4.5, \mathrm{SD}=$ 2.6).

The mean, minimum and maximum ICI were calculated for each group (Table 2). The distribution of ICIs for each sighted group is showed in Fig. 2, and the box plot for the ICIs for each behaviour with the pooled data is shown in
Fig. 3. ICIs emitted by wild bottlenose dolphin were different in feeding, socialising and travelling behaviours: ICIs for feeding $(23.05+35.09 \mathrm{~ms})$, socialising $(117.8+72.9 \mathrm{~ms})$ and travelling $(315.5+208.6 \mathrm{~ms})$.

There were peaks of click trains with very short ICIs, indicating possible foraging behaviour. This was particularly notable in the feeding behaviour data, with $54 \%$ of click trains classified as potential feeding buzzes with minimum ICIs of $<10 \mathrm{~ms}$ only $5.10 \%$ and $3.4 \%$ of ICIs $<10 \mathrm{~ms}$ were present in click trains of socialising and travelling behaviours.

\section{Feeding ICls (ms)}
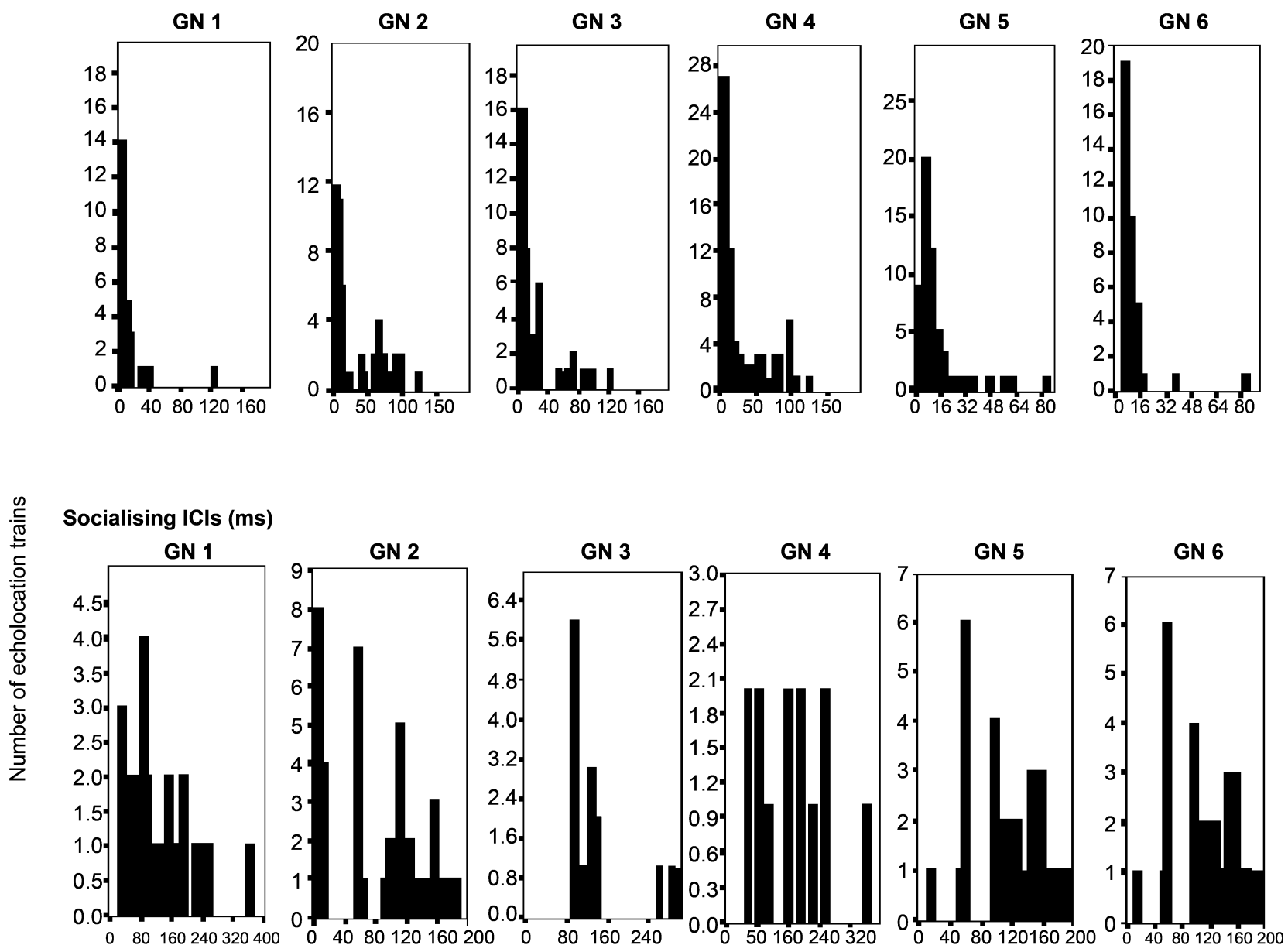

\section{Travelling ICls (ms)}
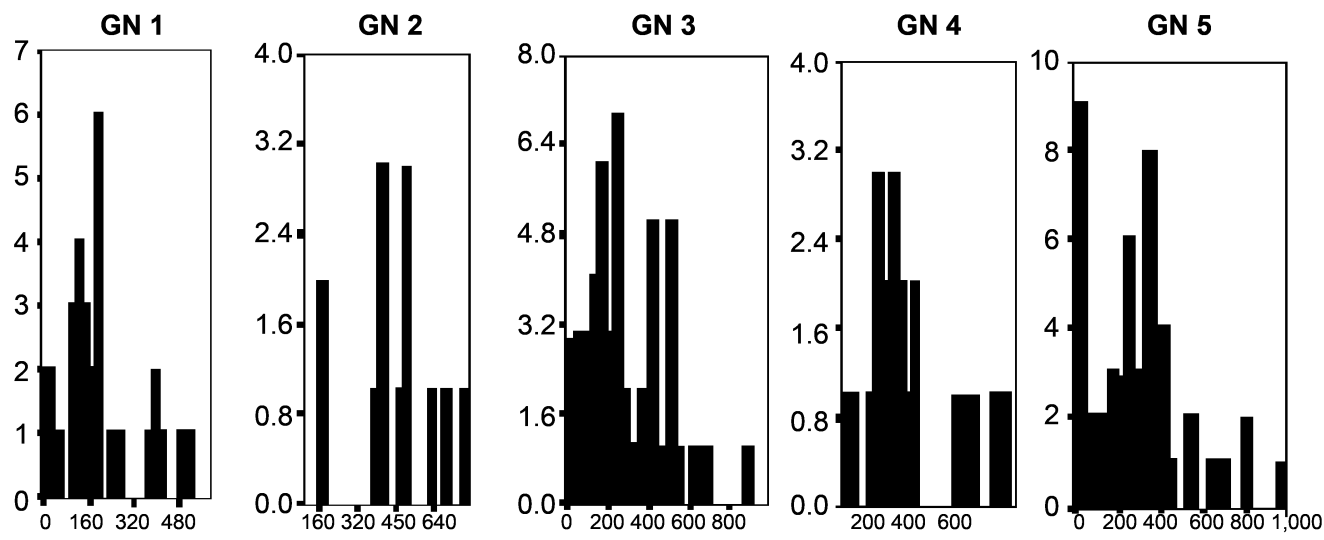

Fig. 2. Histograms of inter-click interval (ICIs) data from 17 groups of bottlenose dolphins. GN = group number identification (see Table 2). 
Table 2

Behaviour identification, median, mean, maximum, minimum and standard deviation of ICI (inter-click interval) for each group and for the total data for each behaviour (GN: group number for each behaviour).

\begin{tabular}{|c|c|c|c|c|c|c|c|}
\hline Group ID & Behaviour & GN & Median ICI (ms) & Mean ICI (ms) & Max ICI (ms) & Min ICI (ms) & $\pm \mathrm{SD}$ ICI \\
\hline Apr-17 & Feeding & 1 & 9 & 44.3 & 126 & 1 & 75.6 \\
\hline Nov-18 & & 2 & 11 & 81.4 & 127 & 3.9 & 96.7 \\
\hline Nov-18 & & 3 & 9.8 & 23.2 & 124 & 1.2 & 29.3 \\
\hline Nov-17 & & 4 & 12.7 & 38.9 & 128 & 1.4 & 38.7 \\
\hline Jan-18 & & 5 & 8 & 11.01 & 84 & 5 & 13.1 \\
\hline Jan-18 & & 6 & 9 & 13.9 & 85 & 2.9 & 15.1 \\
\hline Pooled data & & & 35 & 23.05 & 444 & 1 & 35.9 \\
\hline May-17 & Socializing & 1 & 98 & 122 & 366 & 22 & 84.2 \\
\hline Jun-17 & & 2 & 61 & 79.4 & 189 & 4 & 59.7 \\
\hline Aug-17 & & 3 & 135 & 151.6 & 321 & 47 & 87.8 \\
\hline Feb-18 & & 4 & 127.5 & 135.2 & 289 & 92 & 57.2 \\
\hline Mar-18 & & 5 & 160 & 163.3 & 197 & 48 & 82.1 \\
\hline Mar-18 & & 6 & 150 & 115.5 & 199 & 11 & 46.1 \\
\hline Pooled data & & & 72 & 117.8 & 369 & 4 & 72.9 \\
\hline Sep-17 & Travelling & 1 & 132.5 & 198.1 & 529 & 15 & 90.1 \\
\hline Oct-18 & & 2 & 177.2 & 475 & 781 & 159 & 177 \\
\hline Dec-17 & & 3 & 190.6 & 329 & 789 & 44 & 191 \\
\hline Dec-17 & & 4 & 206.1 & 421 & 832 & 120 & 207 \\
\hline Feb-18 & & 5 & 221.4 & 285.6 & 841 & 3.9 & 221 \\
\hline Pooled data & & & 271 & 315.5 & 841 & 3.9 & 209 \\
\hline
\end{tabular}

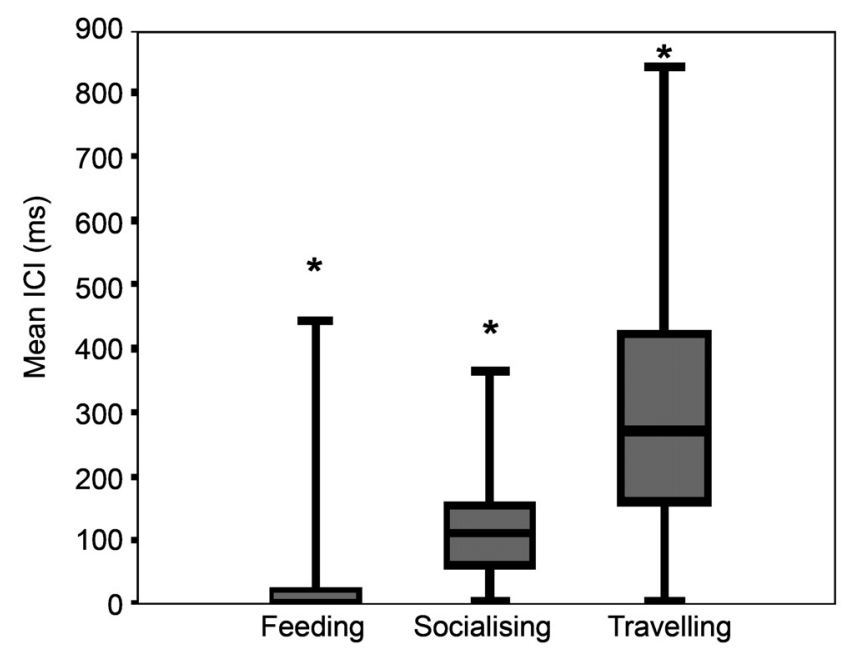

Fig. 3. Mean and standard deviation of ICIs of click trains emitted during feeding, socialising and travelling behaviour in free-ranging bottlenose dolphins.

According to a Kruskal-Wallis test, ICIs were significantly different among behaviours $(\mathrm{p}=3.39 \times 10-39)$, a ManWhitney test showed significant differences among the three behaviours (feeding vs socialising $\mathrm{p}=1.69 \times 10-44$; feeding vs travelling $\mathrm{p}=5.42 \times 10-55$; socialising vs travelling $\mathrm{p}=2.21 \times 10-20)$.

ANOSIM revealed significant differences between ICIs of each category behaviour $(\mathrm{R}=0.621, \mathrm{p}<0.001,999$ permutations). Also, a difference in ICIs was found from the MDS where the three groups are defined (Fig. 4).

\section{DISCUSSION}

There were insufficient visual observation data to assess the click characteristics potentially related to other behavioural categories such as milling or resting, which also form an important part of this species' behaviour (Mann et al., 2000) and that could affect the content and rate of their vocal behaviour. Only the foraging/feeding, socialising and travelling categories were used for analysis in this study, because they were the behaviours that could be successfully monitored at the time of the observations.

The ICIs in the echolocation trains were found to have significant differences in the three different behaviours (feeding, socialising and travelling) in wild bottlenose dolphins (Table 1). The data presented here is also consistent with the echolocation ICIs for foraging animals being larger than for travelling animals where the ICIs are smaller. This matches the findings of previous studies (Nowacek, 2005; Tyack, 2000). In fact, this study shows that for the feeding behaviour $54 \%$ of click trains were classified as potential feeding buzzes with minimum ICIs of $<10 \mathrm{~ms}$. Only $5.10 \%$ and $3.4 \%$ of ICIs $<10 \mathrm{~ms}$ were present in click trains for socialising and travelling behaviours.

Dolphin echolocation trains have different inter-click intervals in different situations depending on many factors such as the distance of interest, difficulty in detecting a target, presence or absence of a target, and on the animal's expectation of finding a specific target (Au, 1993; Ridgway et al., 2015; Wisniewska et al., 2014). Several authors considered the percentage of ICIs $<10 \mathrm{~ms}$ (buzzing) indicative of foraging behaviour (Carlström, 2005; Johnson et al., 2008; Verfuß et al., 2009).

The relationship between target distance and pulse rate has been thoroughly investigated using trained captive dolphins under controlled conditions and dolphins in the wild. In most cases as a dolphin approaches a target, the inter-click interval decreases (Johnson et al., 2004; Ridgway et al., 2015; Wisniewska et al., 2014). This is thought to be a function of the two-way travel time of the echolocation click, plus a lag time, both of which must occur before the next click is produced (Au et al., 1974). This relationship was also found in other studies of free-ranging odontocetes (Akamatsu et al., 2005; Jensen et al., 2009) and suggests that the interclick interval is affected by foraging patterns (Akamatsu et al., 2005; Johnson et al., 2008; Johnson et al., 2004; 


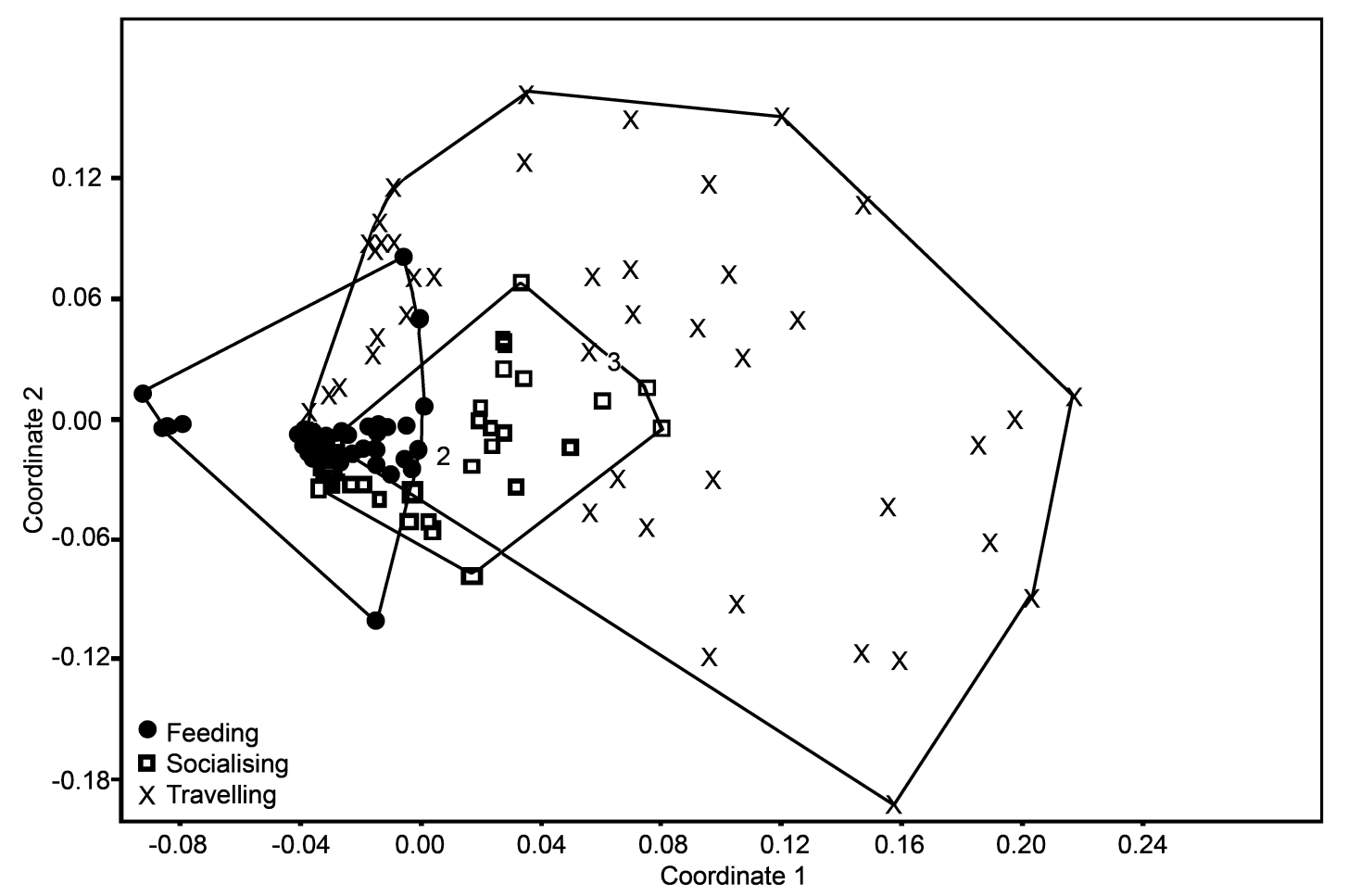

Fig. 4. MDS plot with mean ICIs pooled data for each behaviour.

Madsen et al., 2002) and maybe navigation (Jaquet et al., 2001; Ridgway et al., 2015; Ridgway et al., 2018; Simard et al., 2010; Thode et al., 2002). Therefore echolocation inter-click intervals vary with behaviour (Jones and Sayigh, 2002), and during foraging, bottlenose dolphins produce shorter and faster clicks (termed feeding buzzes) with the shortest ICIs reported between 3.0 and $7.1 \mathrm{~ms}$ (Nuuttila et al., 2013; Ridgway et al., 2015; Ridgway et al., 2018; Ridgway et al., 2014; Wahlberg et al., 2011; Wisniewska et al., 2012). Buzzing has been associated with feeding behaviour (Nowacek, 2005; Tyack, 2000).

In a novel experiment, free-swimming dolphins carried cameras on their heads to record video and sounds during search and capture of fish (see Ridgway et al., 2015). The recordings found buzzes as they captured fish. There are three consistent acoustic phases in prey capture: sonar clicks locate the fish; about $0.4 \mathrm{~s}$ before capture, the dolphin clicks become more rapid to form a second phase, the terminal buzz; at or just before capture, and the buzz turns to an emotional squeal (the victory squeal), which may last 0.2 to 20 s after capture. The squeals are pulse bursts that vary in duration, peak frequency and amplitude.

Other studies have investigated free-ranging odontocete echolocation click rates in relation to assumed foraging patterns (e.g. searching, final approach) (Akamatsu et al., 2005; Johnson et al., 2008; Johnson et al., 2004; Madsen et al., 2002). These results are compatible with the data presented here in which buzzes occurred in a higher percentage in feeding click trains. There is not much information available about ICIs in the socialising behaviour of bottlenose dolphins. Herzing (1996) characterised the sounds recorded by Atlantic spotted dolphin (Stenella frontalis) and bottlenose dolphin in the wild. She describes a genital buzz and burst pulse vocalisation with click trains of very short ICIs. The social uses of click trains included low-frequency buzzing during courtship, aggression, discipline, play, and exploration (Herzing, 2004). Click train source levels are used for tactile stimulation which has been measured in spotted dolphins (Au et al., 1998) and for multiple delphinid species (Au, 1993). The use of click trains with ICIs $<10 \mathrm{~ms}$ suggest that odontocetes use packets of clicks (burst pulse sounds) as a way to provide both social and prey information (Herzing, 2004). Therefore, the ICI data for socialising behaviour is relevant for bottlenose dolphins in the wild.

The data obtained from studies in free-ranging dolphins suggests that inter-click intervals overlap in a variety of behaviours and may indicate multiple purposes such as navigation, foraging on benthic or pelagic prey, and possibly communication, in several dolphin species (Akamatsu et al., 1998; Herzing, 1996; Jensen et al., 2009; Simard et al., 2010; Tellechea et al., 2016).

The ICIs in travelling behaviour in this study are similar to the results of other studies. The animals seem to be interested in interpreting the acoustic scene further ahead, thus requiring more intense clicks with longer ICIs to read echoes from distant targets (Nuuttila et al., 2013). There are several results in odontocetes that show that the variation of clicks (click duration, click interval) could be for navigation and orientation use (Jaquet et al., 2001; Johnson and Tyack, 2003; Thode et al., 2002; Zimmer et al., 2003) and related to the variation of the depth at which the animals are moving which could presumably be an important factor in navigation (Simard et al., 2010).

Past studies show overlapping ICIs with different characteristics in a variety of depths may indicate multiple purposes (Akamatsu et al., 1998; Herzing, 1996; Jensen et al., 2009; Nuuttila et al., 2013; Simard et al., 2010).

Using PAM stations can help to record the ambient sounds of animals. Even though PAM stations cannot record the full 
vocal repertoire produced by bottlenose dolphins, they can still reveal valuable behavioural information about the target species by detecting potential foraging events, or others behaviours. This makes the PAM station particularly useful for long-term monitoring studies and it was successfully used in Uruguay (Tellechea et al., 2014). These devices can be used to identify important areas of cetacean behaviour, particularly, for example, in this region by the franciscana dolphin (Pontoporia blainvillei) (a dolphin species classified as Vulnerable (A3d) by the International Union for Conservation of Nature (IUCN, Reeves et al., 2008)). Several acoustic studies have been carried out on this elusive dolphin (Cremer et al., 2017; Melcon et al., 2012; Tellechea et al., 2014; Tellechea et al., 2016) and it has been demonstrated that its presence can be determined with acoustic data.

This study, looking at free-ranging dolphins, suggests that specific inter-click intervals can be an indicator of the dolphin's underwater behaviour, something that until now has been studied very little in detail. Further studies to extract vocal repertoire and to further understand detailed behaviour (using the PAM station) are recommended. Behavioural observations using visual methods are limited to calm seas and daylight hours, typically during summer months. Acoustic monitoring is the only way to acquire detailed information on behaviour patterns for animals in all seasons and conditions.

\section{ACKNOWLEDGMENTS}

Thanks to Daniela Olsson, Martin Fernandez, Niall Ó Fearghail and Ross Mc Namara, Roy and Alexander Macken for their help in the field and to Dr. Michael Fine for his suggestions on the manuscript, to Estela Baccino who constructed the map, to Área de Anatomía Laboratory, Facultad de Veterinaria, UDELAR and to ANII (Agencia Nacional de Investigación e Innovación) through the National Research System (ANII-SIN-Uruguay) for support. The present work was conducted under the knowledge and authorisation of the Marine Mammals Department (Lic. Alberto Ponce De Leon, Headman) from DINARA (National Direction of Aquatic Resources), Ministry of Livestock, Agriculture and Fisheries, Uruguay. This study did not have any financial grants.

\section{REFERENCES}

Acevedo-Gutiérrez, A. and Stienessen, S.C. 2004. Bottlenose dolphins (Tursiops truncatus) increase number of whistles when feeding. Aquat. Mamm. 30: 357-62. [Available at: http://dx.doi.org/10.1578/AM.30.3. 2004.357].

Aguilar Soto, N., Johnson, M.P., Madsen, P.T., Díaz, F., Domínguez, I., Brito, A. and Tyack, P. 2008. Cheetahs of the deep sea: deep foraging sprints in shortfinned pilot whales off Tenerife (Canary Islands). J. Anim. Ecol. 77: 936-47. [Available at: https://doi.org/10.1111/j.1365-2656. 2008.01393.x]

Akamatsu, T., Wang, D., Nakamura, K. and Wang, K. 1998. Echolocation range of captive and free-ranging baiji (Lipotes vexillifer), finless porpoise (Neophocaena phocaenoides), and bottlenose dolphin (Tursiops truncatus). J. Acoust. Soc. Am. 104: 2511-16. [Available at: https://doi. org/10.1121/1.423757].

Akamatsu, T., Wang, D., Wang, K. and Naito, Y. 2005. Biosonar behaviour of free-ranging porpoises. Proc. R. Soc. Lond. Series B 272: 797-801. [Available at: https://doi.org/10.1098/rspb.2004.3024].

Au, W.W.L. 1993. The Sonar of Dolphins. Springer-Verlag, New York. 277pp. [Available at: https://doi.org/10.1007/978-1-4612-4356-4].
Au, W.W.L., Floyd, R.W. and Haun, J.E. 1978. Propagation of Atlantic bottlenose dolphin echolocation signals. J. Acoust. Soc. Am. 64(2): 41122. [Available at: https://doi.org/10.1121/1.382015].

Au, W.W.L., Floyd, R.W. and Pawloski, D. 1986. Echolocation transmitting beam of the Atlantic bottlenose dolphin. J. Acoust. Soc. Am. 80(2): 66891. [Available at: https://doi.org/10.1121/1.394012].

Au, W.W.L., Floyd, R.W., Penner, R.H. and Murchison, A.E. 1974 Measurement of echolocation signals of the Atlantic bottlenose dolphin, (Tursiops truncatus, Monagu), in open waters. J. Acoust. Soc. Am. 56(4): 1280-90. [Available at: https://doi.org/10.1121/1.1903419].

Au, W.W.L., Herzing, D.L. and Aubauer, R. 1998. Real-time measurement of the echolocation signals of wild dolphins using a 4-hydrophone array. In: Proceedings of The World Marine Mammal Science Conference, Monaco, 20-24 January 1998.

Bearzi, G., Politi, E. and Notarbartolo di Sciara, G. 1999. Diurnal behavior of free-ranging bottlenose dolphins in the Kvarneric (Northern Adriatic Sea). Mar. Mamm. Sci. 15(4): 1065-97. [Available at: https://doi.org/ 10.1111/j.1748-7692.1999.tb00878.x].

Borg, I. and Groenen, P.J.F. 2005. Modern Multidimensional Scaling. 2nd edition. Springer, New York. [Available at: https://doi.org/10.1007/0-38728981-X].

Carlström, J. 2005. Diel variation in echolocation behaviour of wild harbour porpoises. Mar. Mamm. Sci. 21(1): 1-12. [Available at: https://doi.org/ 10.1111/j.1748-7692.2005.tb01204.x].

Cremer, M., Holz, A.C., Bordino, P., Wells, R.S. and Simões-Lopes, P.C. 2017. Social sounds produced by franciscana dolphins, Pontoporia blainvillei (Cetartiodactyla, Pontoporiidae). J. Acoust. Soc. Am. 141: 2047. [Available at: https://doi.org/10.1121/1.4978437].

de Freitas, M., Jensen, F.H., Tyne, J., Bejder, L. and Madsen, P.T. 2015. Echolocation parameters of Australian humpback dolphins (Sousa sahulensis) and Indo-Pacific bottlenose dolphins (Tursiops aduncus) in the wild. J. Acoust. Soc. Am. 137: 3033-41. [Available at: https://doi.org/ 10.1121/1.4921277].

DeRuiter, S.L., Bahr, A., Blanchet, M.A., Hansen, S.F., Kristensen, J.H., Madsen, P.T., Tyack, P.L. and Wahlberg, M. 2009. Acoustic behaviour of echolocating porpoises during prey capture. J. Exp. Biol. 212: 3100-07. [Available at: doi: https://doi.org/10.1242/jeb.030825].

Dibble, D.S., Van Alstyne, K.R. and Ridgway, S. 2016. Dolphins signal success by producing a victory squeal. Int. J. Comp. Psychol. 29: 1-10.

European Cetacean Society. 1993. Annual Conference - Conference guide and abstracts. Eden Court Theatre, Inverness, Scotland, 18-21 February 1993. ECS Newsletter: 64pp.

Finneran, J.J. 2013. Dolphin 'packet' use during long-range echolocation tasks. J. Acoust. Soc. Am. 133: 1796-810. [Available at: https://doi.org/ 10.1121/1.4788997].

Finneran, J.J. 2014. Multi-echo processing by a bottlenose dolphin operating in 'packet' transmission mode at long range. J. Acoust. Soc. Am. 136: 2876-86. [Available at: https://doi.org/10.1121/1.4898043].

Fruet, P., Secchi, E., Daura-Jorge, F., Vermeulen, E., Flores, P., SimoesLopes, P., Genoves, R., Laporta, P., Di Tullio, J.C., Freitas, T., Dalla Rosa, L., Valiati, V.H., Beheregaray, L. and Moller, L. 2014. Remarkably low genetic diversity and strong population structure in common bottlenose dolphins (Tursiops truncatus) from coastal waters of the Southwestern Atlantic Ocean. Conserv. Genet. 15: 879-95. [Available at: https://doi.org/10.1007/s10592-014-0586-z].

Hammer, O., Harper, D.A.T. and Ryan, P.D. 2001. PAST: Paleontological Statistics software package for education and data analysis. Palaeontologia Electronics 4(1): 1-9.

Herzing, D.L. 1996. Underwater behavioral observations and associated vocalizations of free-ranging Atlantic spotted dolphins, Stenella frontalis, and bottlenose dolphin, Tursiops truncatus. Aquat. Mamm. 22(1): 61-79. [Available at: https://doi.org/10.12966/abc.02.02.2015].

Herzing, D.L. 2004. Social and non-social uses of echolocation in freeranging Stenella frontalis and Tursiops truncatus. pp.404-10. In: J.A. Thomas, C.F. Moss and M. Vater (Eds). Echolocation in Bats and Dolphins. University of Chicago Press, Chicago, IL.

Ivanov, M.P. 2004. Dolphin's echolocation signals in a complicated acoustic environment. Acoust. Phys. 50: 550-61. [Available at: https://doi.org/ 10.1134/1.1776226].

Janik, V.M. 2009. Acoustic communication in delphinids pp.123-57. In: M. Naguib and V.M. Janik, V.M. (Eds). Advanced Study in Behaviour. Academic Press, Burlington, VT. [Available at: http://dx.doi.org/10.1016/ S0065-3454(09)40004-4].

Jaquet, N., Dawson, S.M. and Douglas, L. 2001. Vocal behaviour of male sperm whales: why do they click? J. Acoust. Soc. Am. 109: 2254-59. [Available at: https://doi.org/10.1121/1.1360718].

Jensen, F.H., Bejder, L., Wahlberg, M. and Madsen, P.T. 2009. Biosonar adjustments to target range of echolocating bottlenose dolphins (Tursiops sp.) in the wild. J. Exp. Biol. 212: 1078-86. [Available at: https://doi.org/ 10.1242/jeb.025619]. 
Johnson, M., Hickmott, L.S., Aguilar Soto, N. and Madsen, P.T. 2008. Echolocation behaviour adapted to prey in foraging Blainville's beaked whale (Mesoplodon densirostris). Proc. R. Soc. Lond. Series B 275: 133 39. [Availabe at: https://doi.org/10.1098/rspb.2007.1190]

Johnson, M., Madsen, P.T., Zimmer, W.M.X., Aguilar de Soto, N. and Tyack, P.L. 2004. Beaked whales echolocate on prey. Proc. R. Soc. Lond. Series B. 271(S6): 383-86.

Johnson, M. and Tyack, P.L. 2003. A digital acoustic recording tag for measuring the response of wild marine mammals to sound. IEEE $J$. Ocean. Engr. 28: 3-12.

Jones, G.J. and Sayigh, L.S. 2002. Geographic variation in rates of vocal production of free-ranging bottlenose dolphins. Mar. Mamm. Sci. 18(2): 374-93. [Available at: $h$ ttps://doi.org/10.1111/j.1748-7692.2002.tb01044.x].

Kyhn, L.A., Tougaard, J., Jensen, J.F., Wahlberg, M., Stone, G., Yoshinaga, A., Beedholm, K. and Madsen, P.T. 2009. Feeding at a high pitch: Source parameters of narrow band, high-frequency clicks from echolocating offshore hourglass dolphins and coastal Hector's dolphins. J. Acoust. Soc. Am. 125: 1783-91.

Ladegaard, M., Jensen, F.H., Beedholm, K., da Silva, V.M.F. and Madsen, P.T. Amazon river dolphins (Inia geoffrensis) modify biosonar output level and directivity during prey interception in the wild. J. Exp. Biol. 220: 2654-65. [Available at: https://doi.org/10.1242/jeb.159913].

Laporta, P., Fruet, P.F. and Secchi, E.R. 2016. First estímate of common bottlenose dolphin (Tursiops truncatus) (Cetacea, Delphinidae) abundance on Uruguayan Atlantic coast. Lat. Am. J. Aquat. Mamm. 11 144-54. [Available at: $h$ ttps://doi.org/10.5597/00223].

Madsen, P.T. and Surlykke, A. 2013. Functional convergence in bat and toothed whale biosonars. Physiology 28: 276-83. [Available at: https://doi.org/10.1152/physiol.00008.2013].

Madsen, P.T. and Wahlberg, M. 2007. Recording and quantification of ultrasonic echolocation clicks from free-ranging toothed whales. Deep Sea Res. (Part I) 54: 1421-44. [Available at: https://doi.org/10.1016 j.dsr.2007.04.020]

Madsen, P.T., Wahlberg, M. and Møle, B. 2002. Male sperm whale (Physeter macrocephalus) acoustics in a high latitude habitat implications for echolocation and communication. Behav. Ecol. Sociobiol. 53: 31-41. [Available at: https://doi.org/10.1007/s00265-002-0548-1].

Mann, J.C., Connor, R.C., Tyack, P.L. and Whitehead, H. 2000. Cetacean Societies. The University of Chicago Press, Chicago.

Martin, A.R. and Reeves, R.R. 2002. Diversity and zoogeography. pp.1-38. In: A.R. Hoelzel, (Ed.). Marine Mammal Biology: an evolutionary approach. Blackwell Science, Oxford.

Mazzoni, D. 2006. AUDACITY 1.2.6. [Available at: http://audacity. sourceforge.net/

Melcon, M.L., Failla, M. and Iniguez, M.A. 2012. Echolocation behavior of Franciscana dolphins (Pontoporia blainvillei) in the wild. J. Acoust. Soc. Am. 131(6): EL448-EL53 [online]. [Available at: https://doi.org/ 10.1121/1.4710837]

Menchaca, C., Laporta, P. and Tassino, B. 2019. Social structure of Lahille's bottlenose dolphin Tursiops truncatus gephyreus (Cetacea: Delphinae) off the Uruguayan marine coast. Mastozool. Neotrop. 26(2): 410-19. [Available at: $h$ ttps://doi.org/10.31687/saremMN.19.26.2.0.15].

Miller, L.A. 2010. Prey capture by harbour porpoises (Phocoena phocoena): A comparison between echolocators in the field and in captivity. $J$. Acoust. Soc. Japan. 37(3): 156-68.

Miller, P.J.O., Johnson, M.P. and Tyack, P.L. 2004. Sperm whale behaviour indicates the use of echolocation click buzzes 'creaks' in prey capture. Proc. R. Soc. Lond. Series B 271(1554): 2239-247. [Available at: https://doi.org/10.1098/rspb.2004.2863].

Moore, P.W., Dankiewicz, L.A. and Houser, D.S. 2008. Beamwidth control and angular target detection in an echolocating bottlenose dolphin (Tursiops truncatus). J. Acoust. Soc. Am. 124: 3324-32. [Available at: https://doi.org/10.1121/1.2980453].

Nachtigall, P.E. and Moore, P.W.B. 1988. Animal Sonar: Processes and Perfomance. Plenum, New York.

Norris, K.S., Prescott, J.H., Asa-Dorian, P.V. and Perkins, P. 1961. An experimental demonstration of echo-location behavior in the porpoise, Tursiops truncatus (Montagu). Biol. Bull. 120: 163-76. [Available at: https://doi.org/10.2307/1539374].

Nowacek, D.P. 1999. Sound use, sequential behavior and ecology of foraging bottlenose dolphins, Tursiops truncatus (Doctoral dissertation). Massachusetts Institute of Technology and Woods Hole Oceanographic Institution. [Retrieved 13 April 2013 from: https://www.dtic.mil/dtic/ tr/fulltext/u2/a376514.pdf]

Nowacek, D.P. 2005. Acoustic ecology of foraging bottlenose dolphins (Tursiops truncatus), habitat-specific use of three sound types. Mar. Mamm. Sci. 21(4): 587-602. [Available at: https://doi.org/10.1111/j.17487692.2005.tb01253.x].

Nuuttila, H.K., Meier, R., Evans, P.G.H., Turner, J.R., Bennell, J.D. and Hiddink, J.G. 2013. Identifying foraging behaviour of wild bottlenose dolphins (Tursiops truncatus) and harbour porpoise (Phocoena phocoena) with static acoustic dataloggers. Aquat. Mammal. 39(2): 147-61. [Available at: https://doi.org/10.1578/AM.39.2.2013.147].

Ott, P.H., Barreto, A.S., Siciliano, S., Laporta, P., Domit, C., Fruet, P., Dalla Rosa, L., Cesar de Oliveira Santos, M., Meirelles, A.C., Constanza Marchesi, M., Botta, S. and Rosa de Oliveira, L. 2016. Report of the working group on taxonomy and stock identity of bottlenose dolphins in the Southwestern Atlantic Ocean. Lat. Am. J. Aquat. Mamm. 11(1-2): 16-28.

Penner, R.H. 1988. Attention and detection in dolphin echolocation. pp.70714. In: P.E. Nachtigall and P.B. Moore (Eds). Animal Sonar: Processes and Performance. Plenum Press, New York.

Piwetz, S. 2019. Common bottlenose dolphin (Tursiops truncatus) behavior in an active narrow seaport. PLoS One 14(2): e0211971. [Available at: https://doi.org/10.1371/journal.pone.0211971].

Quick, N.J. and Janik, V.M. 2008. Whistle rates of wild bottlenose dolphins: influences of group size and behavior. J. Comp. Psychol. 122: 305-11. [Available at: $h$ ttps://doi.org/10.1037/0735-7036.122.3.305].

Reeves, R.R., Dalebout, M.L. and Jefferson, T.A. 2008. Pontoporia blainvillei. IUCN Red List of Threatened Species. Version 2010.4. [Available at: http://www.iucnredlist.org].

Ridgway, S., Samuelson, D., Vanalstyne, K. and Price, D. 2015. On doing two things at once: dolphin brain and nose coordinate sonar clicks, buzzes and emotional squeals with social sounds during fish capture. J. Exp. Biol. 218: 3987-95. [Available at: https://doi.org/10.1242/jeb.130559].

Ridgway, S.H., Dibble, D.S and Kennemer, J.A. 2018. Timing and context of dolphin clicks during and after mine simulator detection and marking in the open ocean. Biol. Open 2018 7: bio031625. [Available at: https://doi.org/10.1242/bio.031625].

Ridgway, S.H., Moore, P.W., Carder, D.A. and Romano, T.A. 2014. Forward shift of feeding buzz components of dolphins and belugas during associative learning reveals a likely connection to reward expectation, pleasure and brain dopamine activation. J. Exp. Biol. 217: 2910-19. [Available at: https://doi.org/10.1242/jeb.100511].

Shane, S.H. 1990. Behavior and ecology of the bottlenose dolphin at Sanibel Island, Florida. pp.245-66. In: S. Leatherwood and R.R. Reeves (eds). The Bottlenose Dolphin. Academic Press, San Diego, Californa. 653 pp.

Simard, P., Hibbard, A.L., McCallister, K.A., Frankel, A.S., Zeddies, D.G., Sisson, G.M., Gowans, S., Forys, E.A. and Mann, D.A. 2010. Depth dependent variation of the echolocation pulse rate of bottlenose dolphins (Tursiops truncatus). J. Acoust. Soc. Am. 127(1): 568-78. [Available at: https://doi.org/10.1121/1.3257202].

Simard, P., Lace, N., Gowans, S., Quintana-Rizzo, E., Kuczaj, S.A., II, Wells, R.S. and Mann, D.A. 2011. Low frequency narrow-band calls in bottlenose dolphins (Tursiops truncatus): Signal properties, function, and conservation implications. J. Acoust. Soc. Am. 130(5): 3068-76. [Available at: http://dx.doi.org/10.1121/1.3641442].

Surlykke, A. and Nachtigall, P.E. 2014. Biosonar of bats and toothed whales: an overview. In: A. Surlykke, P.E. Nachtigall, R.R. Fay and A.N. Popper (Eds). Biosonar. Springer-Verlag, New York. [Available at: https://doi.org/10.1007/978-1-4614-9146-0].

Tellechea, S.J., Cambon-Tait, D., Bouvier, D. and Norbis, W. 2014. Passive Acoustic Monitoring of bottlenose dolphins (Tursiops truncatus) on the Uruguayan Coast: Vocal characteristics and seasonal cycles. Aquat. Mamm. 40: 173-84. [Available at: https://doi.org/10.1578/AM.40.2. 2014.173].

Tellechea, S.J., Ferreira, M. and Norbis, W. 2016. Echolocation and burst clicks from Franciscana dolphins (Pontoporia blainvillei) on the coast of Uruguay. Mar. Mammal Sci. 33(3): 687-24. [Available at: https://doi.org/ $10.1111 / \mathrm{mms} .12383]$.

Thode, A., Mellinger, D.K., Stienessen, S., Martinez, A. and Mullin, K. 2002. Depth-dependent acoustic features of diving sperm whales (Physeter macrocephalus) in the Gulf of Mexico. J. Acoust. Soc. Am. 112: 308-21. [Available at: https://doi.org/10.1121/1.1482077].

Thomas, J.A. and Kastelein, R.A. 1990. Sensory Abilities of Cetaceans: laboratory and field evidence. A Life Sciences vol., Vol. 196, NATO ASI Series. Plenum Press, New York. 710pp.

Turl, C.W. and Penner, R.H. 1989. Differences in echolocation click patterns of the beluga, (Delphinapteras leucas), and the bottlenose dolphin, (Tursiops truncatus). J. Acoust. Soc. Am. 86(2): 497-502. [Available at: https://doi.org/10.1121/1.398229].

Tyack, P.L. 2000. Functional aspects of cetacean communication. pp.270307. In: J. Mann, J. (Ed.). Cetacean Societies: Field Studies of Dolphins and Whales. University of Chicago Press, Chicago.

Tyack, P.L. and Miller, E.H. 2002. Vocal anatomy, acoustic communication and echolocation. pp.142-84. In: A.R. Hoelzel (Ed.). Marine Mammal Biology: an evolutionary approach. Blackwell Science, Oxford.

Verfuß, U.K., Miller, L.A., Pilz, P.K.D. and Schnitzler, H.-U. 2009. Echolocation by two foraging harbour porpoises (Phocoena phocoena). 
J. Exp. Biol. 212: 823-34. [Available at: https://doi.org/10.1242/ jeb.022137].

Villadsgaard, A., Wahlberg, M. and Tougaard, J. 2007. Echolocation signals of wild harbour porpoises, Phocoena phocoena. J. Exp. Biol. 210: 56-64. [Available at: https://doi.org/10.1242/jeb.02618].

Wahlberg, M., Jensen, F.H., Soto, N.A., Beedholm, K., Bejder, L., Oliveira, C., Rasmussen, M., Simon, M., Villadsgaard, A. and Madsen, P.T. 2011. Source parameters of echolocation clicks from wild bottlenose dolphins (Tursiops aduncus and Tursiops truncatus). J. Acoust. Soc. Am. 130: 2263. [Available at: http://doi.org/10.1121/1.3624822].

Wisniewska, D.M., Johnson, M., Beedholm, K., Wahlberg, M. and Madsen, P.T. 2012. Acoustic gaze adjustments during active target selection in echolocating porpoises. J. Exp. Biol. 215: 4358-73. [Available at: https://doi.org/10.1242/jeb.074013].
Wisniewska, D.M., M., J., E., N.P. and T., M.P. 2014. Buzzing during biosonar-based interception of prey in the delphinids Tursiops truncatus and Pseudorca crassidens. J. Exp. Biol. 217: 4279-82. [Available at: https://doi.org/10.1242/jeb.113415].

Wood, F.G. and Evans, W.E. 1980. Adaptiveness and ecology of echolocation in toothed whales. pp.381-426. In: R.G. Busnel and J.F. Fish (Eds). Animal Sonar Systems. Plenum Press, New York. 1,135pp.

Zar, J.H. 2010. Biostatistical Analysis. 5th Edition, Prentice-Hall/Pearson, Upper Saddle River, NJ. xiii+944pp.

Zimmer, W.M.X., Johnson, M.P., D'Amico, A. and Tyack, P. 2003. Combining data from a multisensor tag and passive sonar to determine the diving behavior of a sperm whale (Physeter macrocephalus). IEEE J. Ocean. Engr. 28: 13-28. [Available at: https://doi.org/10.1109/JOE. 2002.808209]. 